\title{
The influence of smoking exposure and cessation on penile hemodynamics and corporal tissue in a rat model
}

\author{
Jian-Hui Lin ${ }^{1 \#}$, Dong-Ru Ho ${ }^{1 \#}$, Chung-Sheng Shi ${ }^{1,2}$, Chih-Shou Chen ${ }^{1}$, Jhy-Ming Li ${ }^{2,3}$, Yun-Ching Huang ${ }^{1,4}$ \\ ${ }^{1}$ Division of Urology, Department of Surgery, Chang Gung Memorial Hospital, Chiayi; ${ }^{2}$ Graduate Institute of Clinical Medical Sciences, College \\ of Medicine, Chang Gung University, Taoyuan; ${ }^{3}$ Division of Colon and Rectal Surgery, Department of Surgery, Chang Gung Memorial Hospital, \\ Chiayi; ${ }^{4}$ Department of Medicine, College of Medicine, Chang Gung University, Taoyuan \\ Contributions: (I) Conception and design: CS Chen, CS Shi, YC Huang; (II) Administrative support: CS Shi, YC Huang; (III) Provision of study \\ materials or patients: YC Huang; (IV) Collection and assembly of data: JH Lin, DR Ho, JM Li, YC Huang; (V) Data analysis and interpretation: JH \\ Lin, DR Ho, JM Li, YC Huang; (VI) Manuscript writing: All authors; (VII) Final approval of manuscript: All authors. \\ \#These authors contributed equally to this work. \\ Correspondence to: Yun-Ching Huang, MD, PhD. No. 6 Sec. West, Chia-Pu Rd, Pu-Zi City, 613, Chiayi County. Email: chrishyc@gmail.com.
}

\begin{abstract}
Background: While epidemiological studies have clearly documented that smoking cessation significantly enhances sexual health, the underlying mechanism remains largely unknown. Thus, we wished to explore possible mechanisms by using a rat model of smoking-associated erectile dysfunction (ED).

Methods: Forty 8-week old male Sprague-Dawley rats were divided into 4 groups. Ten rats were exposed only to room air (N group). The remaining 30 rats were passively exposed to cigarette smoke over a 12 -week period. At the end of 12 weeks, the smoking $(S, n=10)$ group underwent immediate erectile function testing and were sacrificed. The remaining 20 rats were exposed to room air only for $4(\mathrm{Q} 4 \mathrm{~W}, \mathrm{n}=10)$ or 8 (Q8W, $\mathrm{n}=10$ ) weeks and then underwent erectile function testing and sacrifice. Erectile function was evaluated by measuring intracavernous pressure (ICP) and mean arterial pressure (MAP). After blood collection for serum testosterone determination, rats were sacrificed to obtain corporal tissue for immunohistochemistry.

Results: Mean ICP/MAP ratio was significantly lower in the $\mathrm{S}$ group compared to the $\mathrm{N}$ and Q8W groups $(0.52 \pm 0.11,0.94 \pm 0.05$, and $0.94 \pm 0.12$, respectively, $\mathrm{P}=0.0189)$. Smooth muscle/collagen ratio was also significantly lower in the $\mathrm{S}$ group compared to the $\mathrm{N}$ and $\mathrm{Q} 8 \mathrm{~W}$ groups $(11.8 \pm 0.94,17.5 \pm 1.82$, and $16.4 \pm 0.60$, respectively, $\mathrm{P}=0.0008)$. Oxidative stress and apoptotic indices were significantly higher in the $\mathrm{S}$ group compared to the $\mathrm{N}$ and Q8W groups. Neuronal and endothelial nitric oxide synthases were significantly less expressed in the $\mathrm{S}$ group compared to the $\mathrm{N}$ and $\mathrm{Q} 8 \mathrm{~W}$ groups.
\end{abstract}

Conclusions: Smoking cessation is associated with partial recovery of penile hemodynamics in a rat model of smoking associated ED.

Keywords: Cigarette; smoking; cessation; erectile dysfunction (ED); rat

Submitted Jun 25, 2019. Accepted for publication Nov 29, 2019.

doi: $10.21037 /$ tau.2019.12.45

View this article at: http://dx.doi.org/10.21037/tau.2019.12.45

\section{Introduction}

Erectile dysfunction (ED), defined as consistent or recurrent inability to attain and/or maintain erection sufficient for satisfactory intercourse, is a medical condition that is expected to affect more than 320 million men worldwide by 2025 (1,2). While ED is a benign disorder, it nevertheless adversely affects the quality of life of the patients and their partners (3).

It has been previously demonstrated that tobacco use is a modifiable risk factor for ED (4). For example, in a crosssectional study of Chinese men in Hong Kong, smoking of $\geq 20$ cigarettes daily was associated with a $50 \%$ increase of having ED (5). Moreover, improvement in ED in smokers 
after cessation was observed in a prospective study (6). Specifically, after one year of smoking cessation, $\geq 25 \%$ of ex-smoker had improved erectile function but none of the current smokers. However, although such epidemiological studies have clearly shown that smoking cessation significantly enhances sexual health, the underlying mechanism remains unknown (7).

As such, the present study was designed to investigate the effect of tobacco cessation on penile hemodynamics and histology in a rat model of cigarette smoking (CS)-related ED. We assessed the functional, histological and molecular changes in rats that underwent a period of exposure followed by cessation of exposure for 4 and 8 weeks. Our goals were to elucidate that cessation of tobacco exposure was associated with improved penile hemodynamics and histology.

\section{Methods}

\section{Experimental design}

All animal experiments were approved by the Institutional Animal Care and Use Committee (Approval number: 2012121822, 1 August 2013). All surgeries were performed under Zoletil anesthesia to minimize suffering.

Forty 8-week-old male Sprague-Dawley rats were purchased from BioLASCO Taiwan Co., Ltd (Taipei) and randomly divided into 4 groups. The negative control group (N group) consisted of 10 rats that were exposed to room air for 12 weeks, tested for erectile function, subjected to blood sample collection, and then sacrificed for histology. The experimental group consisted of the remaining 30 rats that were exposed to continuous CS for 2 hours per day, 5 days per week in 12 weeks $(8,9)$. These rats were then randomly and equally divided into 3 groups that were treated as follows: (I) the $\mathrm{S}$ group was tested for erectile function, subjected to blood sample collection, and then sacrificed for histology; (II) the Q4W group was exposed to room air for 4 weeks, tested for erectile function, subjected to blood sample collection, and then sacrificed for histology; (III) the Q8W group was exposed to room air for 8 weeks, tested for erectile function, subjected to blood sample collection, and then sacrificed for histology.

\section{Cigarette smoke exposure}

The procedure was carried out as described previously $(8,9)$. Briefly, rats to be exposed to CS were housed in $28 \times 28 \times 19 \mathrm{~cm}^{3}$ enclosed plastic cages that were connected to a CS-generating device $(8,9)$. The CS was produced from ignited cigarettes that each contained $10 \mathrm{mg}$ of tar and $0.8 \mathrm{mg}$ of nicotine (Marlboro, Philip Morris, Richmond, Virginia, USA). The cigarettes were burned continuously to exhaustion at a rate of one cigarette per 6 minutes.

\section{Erectile function evaluation}

Penile hemodynamic assessment was performed as described previously (10). Briefly, each rat was anesthetized with $20 \mathrm{mg} / \mathrm{kg}$ of Zoletil 50, and their cavernous nerves and penile crus isolated via midline laparotomy. A 23-gauge butterfly needle connected to a pressure transducer and filled with heparinized saline $(200 \mathrm{U} / \mathrm{mL})$ was inserted into penile crus. A bipolar hook electrode was then used to stimulate the cavernous nerves. The stimulation parameters were 50 seconds continuous trains at $1.5 \mathrm{~m} \mathrm{Amp,} 20 \mathrm{~Hz}$ and $0.2 \mathrm{~ms}$ pulse width (A-M Systems, Sequim, WA, USA). For further analysis, the maximum increase of ICP for 3 stimuli per side was utilized for each animal. Penile hemodynamics was reported as the intracavernosal pressure (ICP)/mean arterial pressure (MAP) ratios to normalize for variations in systemic blood pressure.

\section{Immunobistochemical staining}

Penile tissues were processed for immunohistochemical staining as previously described (8-11). Briefly, tissue sections were stained with Masson's trichrome staining, mouse anti-8-hydroxy-2'-deoxyguanosine (8-OHdG, 1:50; JaICA, Nikken Seil Co., Japan), mouse anti- neuronal nitric oxide synthase (nNOS, 1:100; BD Transduction Laboratories, Franklin Lakes, NJ, USA), and terminal deoxynucleotidyl transferasemediated deoxyuridine triphosphate nick-end labeling (TUNEL, Roche Diagnostics Corporation, Indianapolis, IN, USA) using standard techniques.

\section{Western blot analysis}

Details of the Western blotting procedure was described previously $(8,9)$. Briefly, urethral tissue was dissected from the penile sample. Tissue lysates containing $50 \mu \mathrm{g}$ of protein was electrophoresed in $8 \%$ SDS-PAGE, transferred to PVDF membrane (Merck, Darmstadt, Germany), and then incubated with mouse anti-endothelial nitric oxide synthase (eNOS, 1:1,000; BD Biosciences, San Jose, CA, USA) and mouse anti- $\beta$-actin antibody (1:10,000; Santa Cruz, Dallas, 
Table 1 Erectile function studies and testosterone levels in the experimental animals

\begin{tabular}{lccccc}
\hline Group & $\mathrm{N}$ & $\mathrm{S}$ & Q4W & Q8W & P value \\
\hline ICP $\left(\mathrm{cm}-\mathrm{H}_{2} \mathrm{O}\right)$ & $130 \pm 9.5^{\star}$ & $73 \pm 15.7$ & $99 \pm 23.0$ & $131 \pm 9.4^{*}$ & 0.0260 \\
MAP $\left(\mathrm{cm}-\mathrm{H}_{2} \mathrm{O}\right)$ & $137 \pm 7.7$ & $138 \pm 6.1$ & $148 \pm 5.3$ & $148 \pm 9.7$ & 0.5940 \\
ICP/MAP ratios & $0.94 \pm 0.05^{\star}$ & $0.52 \pm 0.11$ & $0.64 \pm 0.14$ & $0.94 \pm 0.12^{\star}$ & 0.0189 \\
Testosterone $(\mathrm{ng} / \mathrm{mL})$ & $6.1 \pm 0.85$ & $3.3 \pm 0.34$ & $5.6 \pm 0.91$ & $6.5 \pm 0.77^{\star}$ & 0.0371 \\
\hline
\end{tabular}

Eight to ten rats were selected for analysis from each group. Data are expressed as mean \pm standard error of the mean. ${ }^{*}$, versus $S$ group $\mathrm{P}<0.05$. Italicized $\mathrm{P}$ values indicate statistical significance. $\mathrm{N}$, exposed only to room air for 12 weeks; $\mathrm{S}$, smoke exposure for a full 12 weeks followed by immediate erectile function testing; Q4W, smoke exposure for 12 weeks followed by 4 weeks of room air only exposure before erectile function testing; Q8W, smoke exposure for 12 weeks followed by 8 weeks of room air only exposure before erectile function testing; ICP, intracavernous pressure; MAP, mean arterial pressure.

Texas). Detection of reactive antigens was performed with ECL kit (Amersham Life Sciences, Pittsburgh, PA, USA). The resulting images were quantified by densitometry.

\section{Image and statistical analysis}

Image results were analyzed with Image-Pro software (Media Cybernetics, Silver Spring, MD, USA) and ACT1 software (Nikon Instruments Inc., Melville, NY, USA). To evaluate $8-\mathrm{OHdG}$ and nNOS, approximately one half of each corporal body was photographed at $\times 40$ magnification and the results were expressed as the percentage of positive area $v s$. total area of the corpora cavernosa. For quantification of Masson's trichrome staining, the specimens were assessed at $\times 40$ magnification and data were expressed as the percentage of smooth muscle normalized to collagen content. For quantifying TUNEL staining, the bilateral corpora cavernosa were analyzed at $\times 100$ magnification and the results were expressed as the number of TUNELpositive nuclei in the corpora cavernosa.

Data were analyzed with Prism version 6 (GraphPad Software, La Jolla, CA, USA) and expressed as mean \pm standard error of the mean (SEM) for all continuous variables. Statistical analyses were performed using oneway analysis of variance, followed by the Tukey-Kramer test for post hoc comparisons. Statistical significance was considered at $\mathrm{P}<0.05$.

\section{Results}

\section{Erectile function and serum testosterone}

Table 1 summarizes erectile function and serum testosterone levels. Mean ICP and ICP/MAP ratios were significantly lower in the $\mathrm{S}$ group compared to the $\mathrm{N}$ and Q8W groups
( $\mathrm{P}=0.0260$ and $\mathrm{P}=0.0189$, respectively). While the $\mathrm{Q} 4 \mathrm{~W}$ group also had higher mean ICP and ICP/MAP ratios than the $S$ group, the difference did not reach statistical significance $(\mathrm{P}=0.4549$ and $\mathrm{P}=0.2536$, respectively). Representative peak ICP graphs are shown in Figure 1.

Serum testosterone was significantly lower in the $\mathrm{S}$ group than in the $\mathrm{Q} 8 \mathrm{~W}$ group $(\mathrm{P}=0.0371)$. Although there was no statistically significant difference between $\mathrm{N}$ and $\mathrm{S}$ groups $(\mathrm{P}=0.0884)$, there was a trend towards decreased testosterone level in CS-exposed rats.

\section{Oxidative stress}

As illustrated in Table 2, expression of 8-OHdG (one of the predominant forms of free radical-induced oxidative DNA damage products) in the $\mathrm{S}$ group was significantly higher than in the $\mathrm{N}$ and $\mathrm{Q} 8 \mathrm{~W}$ groups $(\mathrm{P}=0.0001)$. Significant difference in $8-\mathrm{OHdG}$ expression was also noted between the $\mathrm{N}$ and $\mathrm{Q} 4 \mathrm{~W}$ groups $(\mathrm{P}=0.0018)$. No significant difference was observed between the $\mathrm{S}$ and Q4W groups. Representative images are shown in Figure 2.

\section{nNOS positivity}

As shown in Table 2, intracorporal nNOS was significantly lower in the $\mathrm{S}$ group than in the $\mathrm{N}$ and Q8W groups $(\mathrm{P}=0.0155)$. There was no significant difference in nNOS-positive staining between the $\mathrm{N}$ and Q8W groups $(\mathrm{P}=0.8324)$. Representative images of nNOS staining are shown in Figure 3.

\section{eNOS Western blot}

As presented in Figure 4, protein expression of eNOS was 

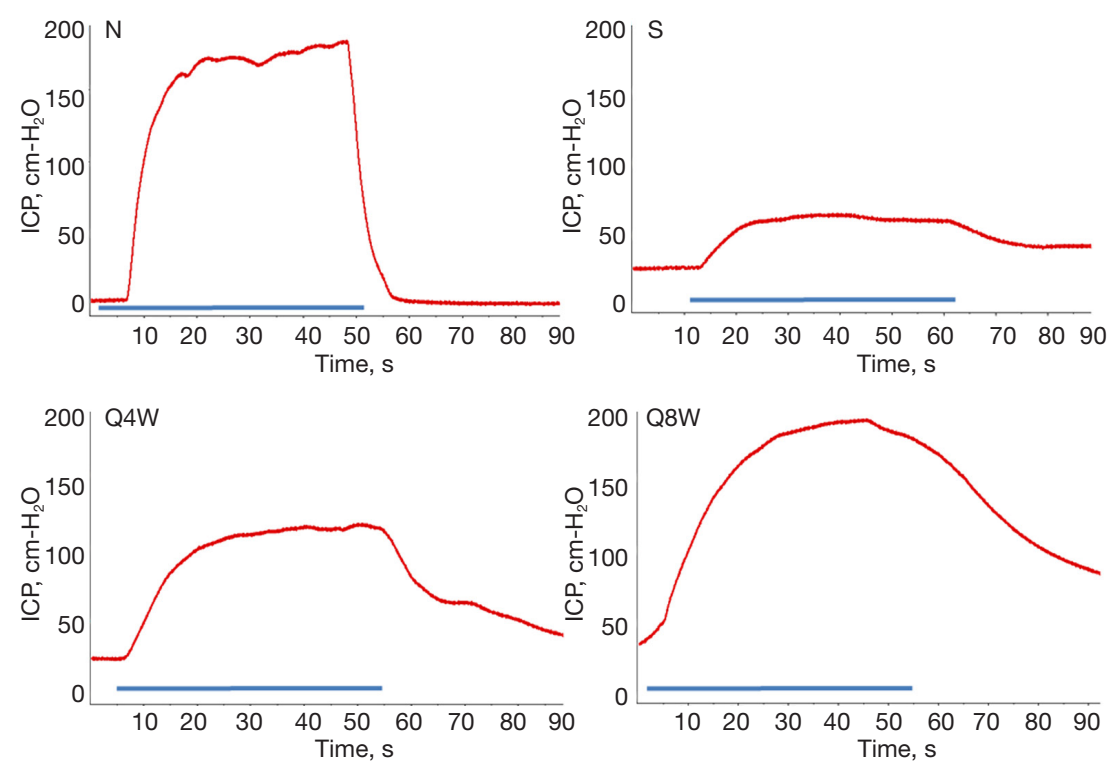

Figure 1 Measurement of erectile function. Representative graphs are shown for rats with exposure only to room air for 12 weeks (N), smoke exposure for a full 12 weeks followed by immediate erectile function testing (S), smoke exposure for 12 weeks followed by 4 weeks of room air only exposure before erectile function testing (Q4W) and smoke exposure for 12 weeks followed by 8 weeks of room air only exposure before erectile function testing $(\mathrm{Q} 8 \mathrm{~W})$. The red curve and blue bar represent intracavernous pressure (ICP) values and the duration of cavernous nerve stimulation ( 50 seconds), respectively.

Table 2 8-OHdG, nNOS, Masson's trichrome and TUNEL stain

\begin{tabular}{|c|c|c|c|c|c|}
\hline Group & $\mathrm{N}$ & $S$ & Q4W & Q8W & $P$ value \\
\hline nNOS percentage (\%) & $20.6 \pm 1.61^{*}$ & $12.5 \pm 1.73$ & $19.0 \pm 1.75$ & $21.1 \pm 2.49^{\star}$ & 0.0155 \\
\hline SM/collagen ratio (\%) & $17.5 \pm 1.82^{*}$ & $11.8 \pm 0.94$ & $11.8 \pm 0.74^{\star \star}$ & $16.4 \pm 0.60^{\star}$ & 0.0008 \\
\hline TUNEL (number) & $18.3 \pm 3.95^{\star}$ & $60.9 \pm 14.28$ & $49.8 \pm 10.45$ & $24.3 \pm 6.07^{*}$ & 0.0113 \\
\hline
\end{tabular}

Eight to ten rats were selected for analysis from each group. Data are expressed as mean \pm standard error of the mean. ${ }^{*}$, versus $\mathrm{S}$ group $\mathrm{P}<0.05 ;{ }^{* *}$, versus $\mathrm{N}$ group $\mathrm{P}<0.05$. Italicized $\mathrm{P}$ values indicate statistical significance. $\mathrm{N}$, exposed only to room air for 12 weeks; $\mathrm{S}$, smoke exposure for a full 12 weeks followed by immediate erectile function testing; Q4W, smoke exposure for 12 weeks followed by 4 weeks of room air only exposure before erectile function testing; Q8W, smoke exposure for 12 weeks followed by 8 weeks of room air only exposure before erectile function testing; 8-OHdG, 8-hydroxy-2'-deoxyguanosine; nNOS, neuronal nitric oxide synthase; SM, smooth muscle; TUNEL, terminal deoxynucleotidyl transferase dUTP nick-end labeling.

significantly lower in the $\mathrm{S}$ group relative to the $\mathrm{N}$ and Q8W groups $(0.08 \pm 0.007$ vs. $0.25 \pm 0.046$ vs. $0.22 \pm 0.041$, $\mathrm{P}=0.024)$; significant differences between the $\mathrm{N}$ and $\mathrm{Q} 4 \mathrm{~W}$ groups were noted for eNOS $(0.25 \pm 0.046$ vs. $0.13 \pm 0.016$, $\mathrm{P}=0.0369)$. No significant difference in eNOS expression was observed between the $\mathrm{N}$ and $\mathrm{Q} 8 \mathrm{~W}$ groups $(\mathrm{P}=0.569)$.

\section{Smooth muscle content}

The smooth muscle to collagen ratio was significantly lower in the $\mathrm{S}$ group compared to the $\mathrm{N}$ and $\mathrm{Q} 8 \mathrm{~W}$ groups $(\mathrm{P}=0.0008)$. Significant difference was also noted between the $\mathrm{N}$ and $\mathrm{Q} 4 \mathrm{~W}$ groups $(\mathrm{P}=0.0061$, Table 2). There was no significant difference between the $\mathrm{N}$ and Q8W groups $(\mathrm{P}=0.7636)$. Representative images are shown in Figure 5.

\section{TUNEL immunobistochemistry}

TUNEL-positive cells were significantly more numerous in the $\mathrm{S}$ group compared to the $\mathrm{N}$ and $\mathrm{Q} 8 \mathrm{~W}$ groups $(\mathrm{P}=0.0113$, 

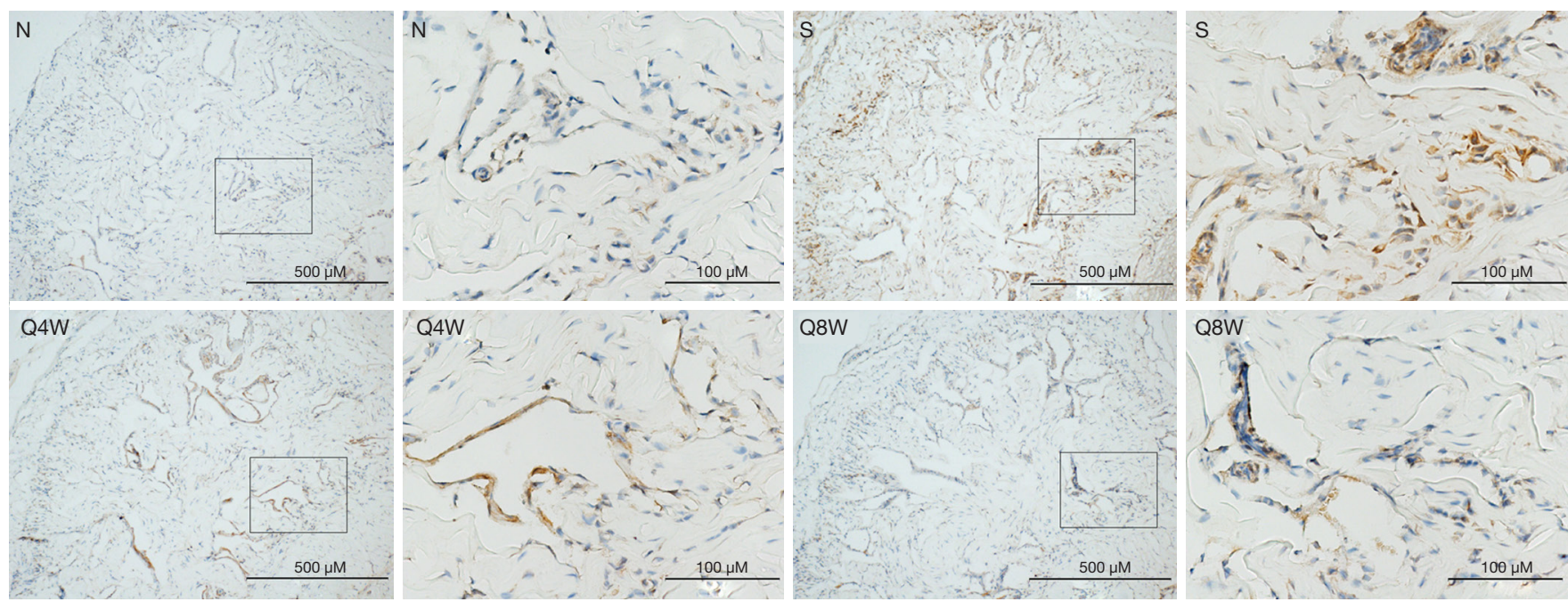

Figure 2 Oxidative stress in corpora cavernosa. Representative images from rats with exposure only to room air for 12 weeks (N), smoke exposure for a full 12 weeks followed by immediate erectile function testing (S), smoke exposure for 12 weeks followed by 4 weeks of room air only exposure before erectile function testing $(\mathrm{Q} 4 \mathrm{~W})$ and smoke exposure for 12 weeks followed by 8 weeks of room air only exposure before erectile function testing $(\mathrm{Q} 8 \mathrm{~W})$. Free radical-induced oxidative DNA damage products are stained brown with 8-OHdG antibody. Positive staining was more intense in the S group than in the $\mathrm{N}$ and Q8W groups. (Scale bars: left, $500 \mu \mathrm{m} ;$ right, $100 \mu \mathrm{m}$ ).
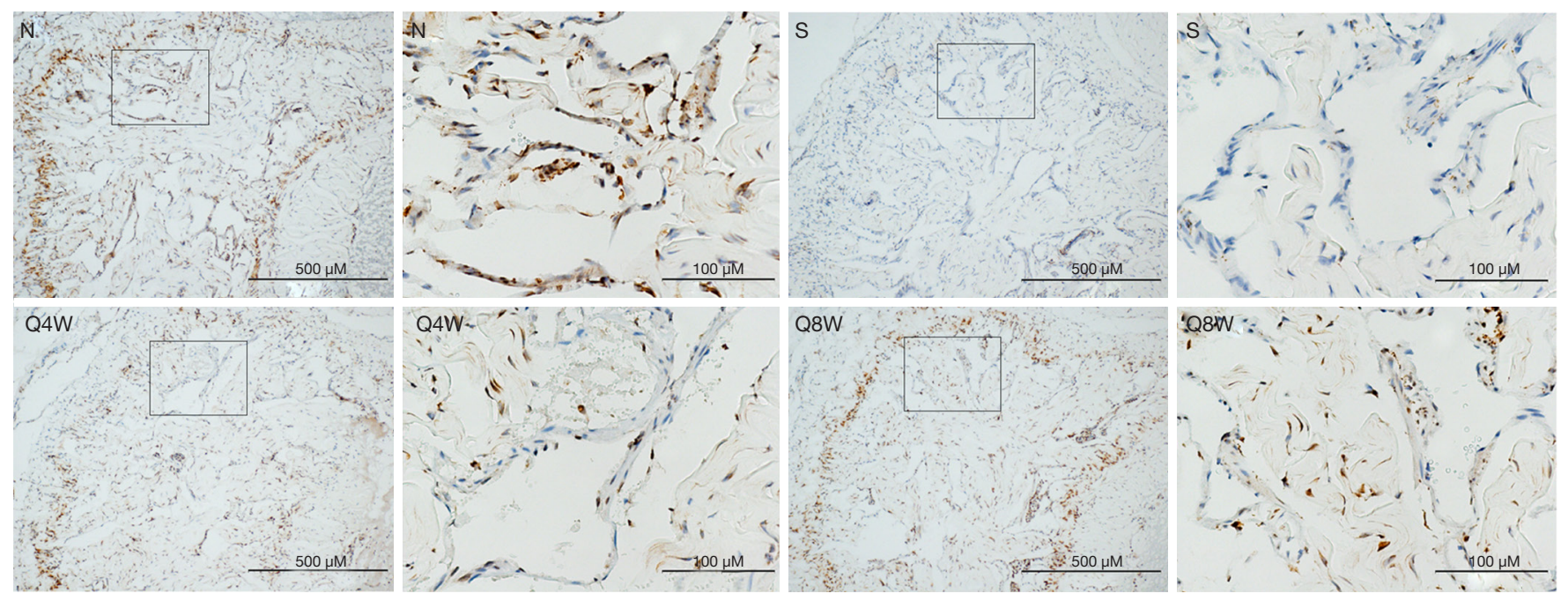

Figure 3 Neuronal nitric oxide synthase (nNOS) in corpora cavernosa. Representative images from rats with exposure only to room air for 12 weeks (N), smoke exposure for a full 12 weeks followed by immediate erectile function testing (S), smoke exposure for 12 weeks followed by 4 weeks of room air only exposure before erectile function testing (Q4W) and smoke exposure for 12 weeks followed by 8 weeks of room air only exposure before erectile function testing (Q8W). nNOS-positive fibers are strained brown with nNOS antibody. Positive staining for nNOS was less intense in the $\mathrm{S}$ group than in the $\mathrm{N}$ and Q8W groups. (Scale bars: left, $500 \mu \mathrm{m}$; right, $100 \mu \mathrm{m}$ ). 


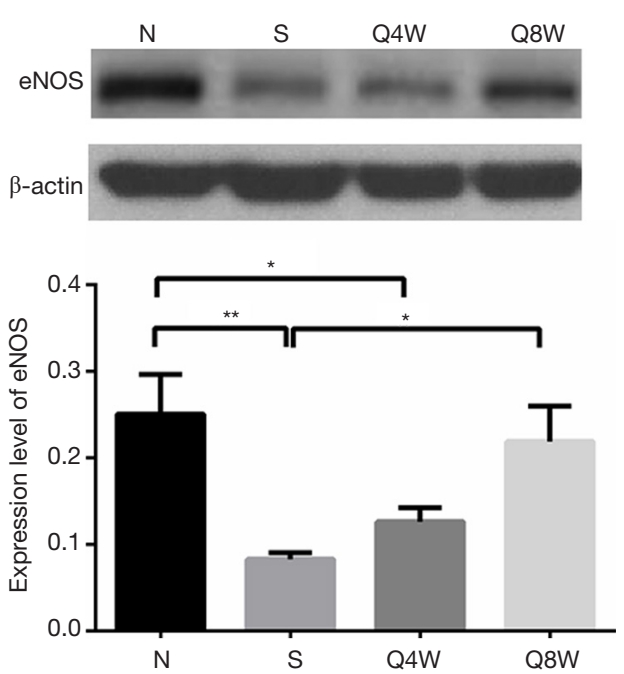

Figure 4 Western blot for endothelial nitric oxide synthase (eNOS). Representative images from rats with exposure only to room air for 12 weeks $(\mathrm{N})$, smoke exposure for a full 12 weeks followed by immediate erectile function testing $(\mathrm{S})$, smoke exposure for 12 weeks followed by 4 weeks of room air only exposure before erectile function testing $(\mathrm{Q} 4 \mathrm{~W})$ and smoke exposure for 12 weeks followed by 8 weeks of room air only exposure before erectile function testing $(\mathrm{Q} 8 \mathrm{~W})$. Mean eNOS was significantly lower in the S group compared with $\mathrm{N}$ and Q8W groups; significant differences between the $\mathrm{N}$ and $\mathrm{Q} 4 \mathrm{~W}$ groups were also noted. (*, $\mathrm{P}<0.05$; **, $\mathrm{P}<0.01)$.

Table 2). There was no significant difference between the $\mathrm{N}$ and $\mathrm{Q} 8 \mathrm{~W}$ groups $(\mathrm{P}=0.6732)$. Representative images are shown in Figure 6.

\section{Discussion}

It has been shown that cigarette smoking is dosedependently associated with ED, and smoking cessation can lead to recovery of erectile function $(6,12)$. However, the underlying mechanisms responsible for the development of ED or for the recovery of erectile function are largely unknown. Thus, we wished to fill this knowledge gap in the present study by establishing animal models that mimic human smoking and smoking cessation, followed by examining their penile tissues for possible changes in key cellular and molecular markers, such as oxidative stress and apoptotic index, nNOS and eNOS expressions, and cavernosal smooth muscle content.

There are more than 4,000 volatile chemicals other than nicotine present in cigarette smoke, many of which have not been evaluated in terms of effects on steroidogenesis (13). There have been conflicting reports of the effects of tobacco on serum testosterone levels (14-16). These conflicting results may be attributable to variability in laboratory methods, time of specimen collection, or other factors. Oyeyipo et al. demonstrated that nicotine administration significantly decreased $(\mathrm{P}<0.05)$ serum testosterone in rats in a dose-dependent fashion; nicotine cessation mitigated some of this effect (17). Our study supports these prior findings. Whether nicotine or another component of tobacco smoke was the driver of this effect remains unclear and a topic for further investigation.

It has been shown that smoking-related ED is associated with an increase in reactive oxygen species, and these free radicals cause ultrastructural damage to the corporal tissue and alter NOS activities in mice, rats, and humans $(8,18,19)$. In our previous studies, CS-exposed animals had higher levels of systemic oxidative stress when compared to control animals (8). In the present study, we further confirmed that CS-exposed animals had higher levels of 8-OHdG expression in penile tissue and this was ameliorated by smoking cessation. We thus hypothesize that oxidative stress is a fundamental underlying mechanism for tobaccoinduced impairment of penile hemodynamics.

Cigarette smoking is a leading global public health concern, especially because of its increasing prevalence among adolescents and young adults (20). Also noteworthy is that tobacco use is more prevalent in Asian compared to Western nations, and this can perhaps explain the higher prevalence of ED in Asian countries when compared to Western countries $(5,21,22)$.

The health benefits of tobacco cessation in terms of prevention of cancer and cardiac disease are well known. However, the potential impact of tobacco use on erectile function is much less known. Given the importance of sexuality to most men, advice that tobacco cessation may help preserve erectile function may be a more powerful motivator for quitting than the more abstract and long-term risks of cancer and heart disease. Thus, findings from the present study may serve as a novel means of commanding more attention and creating stronger motivation especially for Chinese and other Asian populations to stop smoking.

There are several limitations in the present study. For example, the nature of CS exposure in our animal model does not faithfully reflect the typical human CS exposure of repeated short doses throughout a day. Another critical question is how the CS-induced systemic stress might affect the outcome. We hope to address these important questions 


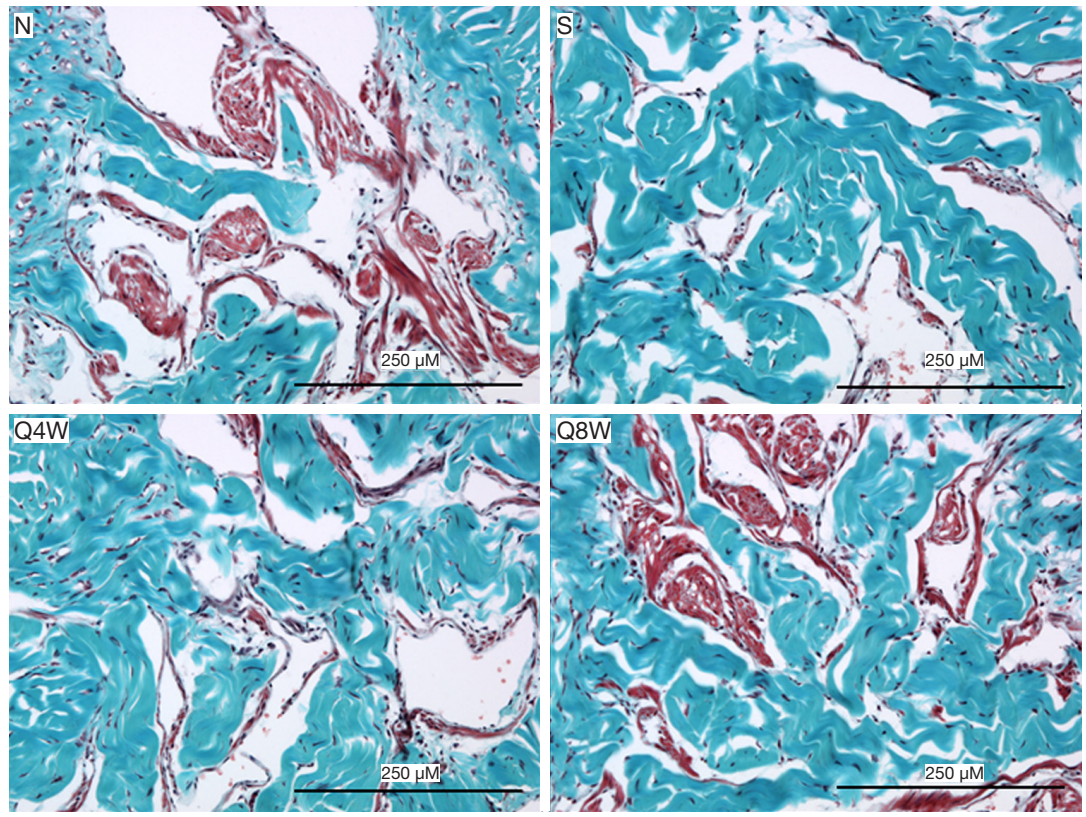

Figure 5 Smooth muscle content in corpora cavernosa. Representative images from rats with exposure only to room air for 12 weeks (N), smoke exposure for a full 12 weeks followed by immediate erectile function testing (S), smoke exposure for 12 weeks followed by 4 weeks of room air only exposure before erectile function testing $(\mathrm{Q} 4 \mathrm{~W})$ and smoke exposure for 12 weeks followed by 8 weeks of room air only exposure before erectile function testing $(\mathrm{Q} 8 \mathrm{~W})$. Smooth muscle and connective tissue are stained with red and blue, respectively, using the trichrome method. The smooth muscle content was less in the S and Q4W groups than in the $\mathrm{N}$ and Q8W groups. The scale bar represents $250 \mu \mathrm{m}$.
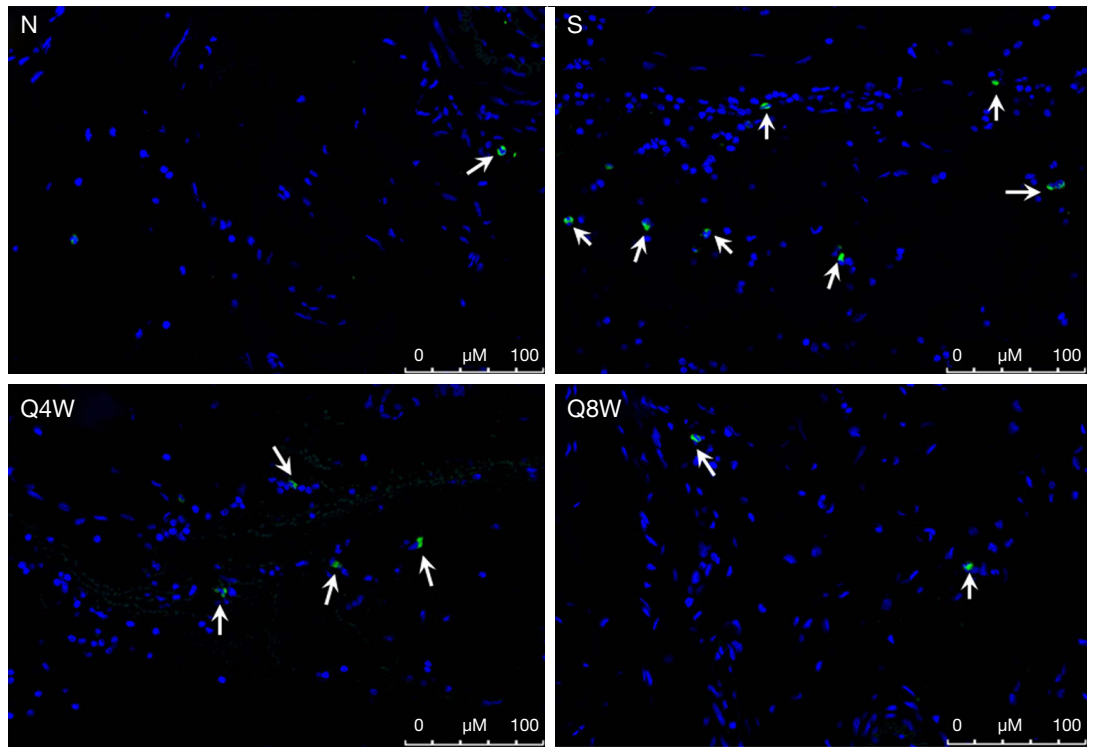

Figure 6 Analysis of apoptosis-positive cells by TUNEL stain. Representative images from rats with exposure only to room air for 12 weeks (N), smoke exposure for a full 12 weeks followed by immediate erectile function testing (S), smoke exposure for 12 weeks followed by 4 weeks of room air only exposure before erectile function testing (Q4W) and smoke exposure for 12 weeks followed by 8 weeks of room air only exposure before erectile function testing $(\mathrm{Q} 8 \mathrm{~W})$. Apoptotic cells and cell nuclei in the corpora cavernosa were visualized with TUNEL staining (green, arrows) and 4',6-diamidino-2-phenylindole staining (blue), respectively. The S group had a greater number of apoptotic cells than the $\mathrm{N}$ and Q8W groups. The scale bar represents $100 \mu \mathrm{m}$. 
in our future research.

To our best knowledge, this study is the first to evaluate the effects of tobacco on erectile function and tissue structure in a rat model. Our findings suggest that smoking cessation is an important component of the therapeutic approach to ED, and healthcare providers should advise patients that stop smoking is not only beneficial for their heart and lung but also for their sexual capability.

\section{Conclusions}

We confirmed that chronic CS exposure increases penile oxidative stress and apoptosis, and decreases nNOS, eNOS and smooth muscle components in corporal tissue. We also uncovered that tobacco cessation is associated with partial recovery of penile hemodynamics. We thus hypothesize that smoking cessation may ameliorate $\mathrm{ED}$ via reduction in oxidative stress. While this in vivo model demonstrated the benefits of smoking cessation, further studies are required to verify the responsible molecular mechanisms.

\section{Acknowledgments}

The authors thank Alan W. Shindel, MD, MAS and ChingShwun Lin, PhD for editorial assistance in manuscript preparation.

Funding: The work was supported by Chang Gung Medical Foundation, Taiwan (CMRP G6H0471).

\section{Footnote}

Conflicts of Interest: All authors have completed the ICMJE uniform disclosure form (available at http://dx.doi. org/10.21037/tau.2019.12.45). The authors have no conflicts of interest to declare.

Ethical Statement: The authors are accountable for all aspects of the work in ensuring that questions related to the accuracy or integrity of any part of the work are appropriately investigated and resolved. The study was approved by the Institutional Animal Care and Use Committee of the Laboratory Animal Center at Laboratory Animal Center, Department of Medical Research, Chang Gung Memorial Hospital at Chiayi (Approval number: 2012121822).

Open Access Statement: This is an Open Access article distributed in accordance with the Creative Commons
Attribution-NonCommercial-NoDerivs 4.0 International License (CC BY-NC-ND 4.0), which permits the noncommercial replication and distribution of the article with the strict proviso that no changes or edits are made and the original work is properly cited (including links to both the formal publication through the relevant DOI and the license). See: https://creativecommons.org/licenses/by-nc$\mathrm{nd} / 4.0 /$.

\section{References}

1. NIH Consensus Conference. Impotence. NIH Consensus Development Panel on Impotence. JAMA 1993;270:83-90.

2. Ayta IA, McKinlay JB, Krane RJ. The likely worldwide increase in erectile dysfunction between 1995 and 2025 and some possible policy consequences. BJU Int 1999;84:50-6.

3. Mulhall JP, Giraldi A, Hackett G, et al. The 2018 Revision to the Process of Care Model for Evaluation of Erectile Dysfunction. J Sex Med 2018;15:1280-92.

4. Shamloul R, Ghanem H. Erectile dysfunction. Lancet 2013;381:153-65.

5. Lam TH, Abdullah AS, Ho LM, et al. Smoking and sexual dysfunction in Chinese males: findings from men's health survey. Int J Impot Res 2006;18:364-9.

6. Pourmand G, Alidaee MR, Rasuli S, et al. Do cigarette smokers with erectile dysfunction benefit from stopping?: a prospective study. BJU Int 2004;94:1310-3.

7. Maiorino MI, Bellastella G, Esposito K. Lifestyle modifications and erectile dysfunction: what can be expected? Asian J Androl 2015;17:5-10.

8. Huang YC, Chin CC, Chen CS, et al. Chronic Cigarette Smoking Impairs Erectile Function through Increased Oxidative Stress and Apoptosis, Decreased nNOS, Endothelial and Smooth Muscle Contents in a Rat Model. PLoS One 2015;10:e0140728.

9. Huang YC, Kuo YH, Huang YH, et al. The Effects of Adipose-Derived Stem Cells in a Rat Model of Tobacco-Associated Erectile Dysfunction. PLoS One 2016;11:e0156725.

10. Huang YC, Ho DR, Lin JH, et al. Dietary Modification Is Associated with Normalization of Penile Hemodynamics in Rats Fed a High-Fat Diet. J Sex Med 2019;16:791-802.

11. Huang YC, Ning H, Shindel AW, et al. The effect of intracavernous injection of adipose tissue-derived stem cells on hyperlipidemia-associated erectile dysfunction in a rat model. J Sex Med 2010;7:1391-400.

12. Polsky JY, Aronson KJ, Heaton JP, et al. Smoking and 
other lifestyle factors in relation to erectile dysfunction. BJU Int 2005;96:1355-9.

13. Dechanet C, Anahory T, Mathieu Daude JC, et al. Effects of cigarette smoking on reproduction. Hum Reprod Update 2011;17:76-95.

14. Zhao J, Leung JY, Lin SL, et al. Cigarette smoking and testosterone in men and women: A systematic review and meta-analysis of observational studies. Prev Med 2016;85:1-10.

15. Halmenschlager G, Rossetto S, Lara GM, et al. Evaluation of the effects of cigarette smoking on testosterone levels in adult men. J Sex Med 2009;6:1763-72.

16. Mitra A, Chakraborty B, Mukhopadhay D, et al. Effect of smoking on semen quality, FSH, testosterone level, and CAG repeat length in androgen receptor gene of infertile men in an Indian city. Syst Biol Reprod Med 2012;58:255-62.

17. Oyeyipo IP, Raji Y, Bolarinwa AF. Nicotine alters male reproductive hormones in male albino rats: The role of

Cite this article as: Lin JH, Ho DR, Shi CS, Chen CS, Li JM, Huang YC. The influence of smoking exposure and cessation on penile hemodynamics and corporal tissue in a rat model. Transl Androl Urol 2020;9(2):637-645. doi: 10.21037/tau.2019.12.45 cessation. J Hum Reprod Sci 2013;6:40-4.

18. Tostes RC, Carneiro FS, Lee AJ, et al. Cigarette smoking and erectile dysfunction: focus on NO bioavailability and ROS generation. J Sex Med 2008;5:1284-95.

19. Bivalacqua TJ, Sussan TE, Gebska MA, et al. Sildenafil inhibits superoxide formation and prevents endothelial dysfunction in a mouse model of secondhand smoke induced erectile dysfunction. J Urol 2009;181:899-906.

20. Warren CW, Jones NR, Eriksen MP, et al. Patterns of global tobacco use in young people and implications for future chronic disease burden in adults. Lancet 2006;367:749-53.

21. Laumann EO, Nicolosi A, Glasser DB, et al. Sexual problems among women and men aged $40-80 \mathrm{y}$ : prevalence and correlates identified in the Global Study of Sexual Attitudes and Behaviors. Int J Impot Res 2005;17:39-57.

22. Ng EM, Cheng JY. Prevalence and biopsychosocial correlates of erectile dysfunction in Hong Kong: a population-based study. Urology 2007;70:131-6. 